Supplementary Information (SI)

\title{
Ratiometric Semiconducting Polymer Nanoparticle for Reliable Photoacoustic Imaging of Pneumonia- induced Vulnerable Atherosclerotic Plaque in Vivo
}

Yuan Ma, ${ }^{\ddagger \dagger}$ Li Xu, ${ }^{\ddagger}$ Baoli Yin, ${ }^{\dagger}$ Jinhui Shang, ${ }^{\dagger}$ Fangfang Chen, ${ }^{\dagger}$ Juntao Xu, ${ }^{\dagger}$

Zhi-ling Song, s Bin Nan, ${ }^{+}$Guosheng Song ${ }^{*}$ and Xiao-bing Zhang ${ }^{*}$

tState Key Laboratory for Chemo/ Bio-Sensing and Chemometrics, College of

Chemistry and Chemical Engineering, Hunan University, Changsha, 410082,

China

§Key Laboratory of Optic-electric Sensing and Analytical Chemistry for Life

Science MOE Shandong Key Laboratory of Biochemical Analysis, College of

Chemistry and Molecular Engineering, Qingdao University of Science and

Technology Qingdao 266042, China

‡Those authors were contributed equally to this work.

‘Corresponding Author: E-mail: songgs@hnu.edu.cn; xbzhang@hnu.edu.cn. 


\section{Supplementary Experiment Section}

Materials and Characterization. All the chemical materials used in the experiment were purchased from commercial suppliers. Tetrakis(triphenylphosphine) palladium (0) and chloroform-d were purchased from Tianjin Heowns Biochemical Technology Co., Ltd. Lipopolysaccharide (LPS) was purchased from Sigma-Aldrich. Ultrapure water was obtained from the Milli-Q system. The silica gel (200-300 mesh) used for column chromatography was purchased from Yantai Jiangyou Silica Gel Development Co., Ltd.

The hydrodynamic size was measured by Malvern Zetasizer Nano ZS90 (Malvern). The absorbance was recorded by uv-vis absorption spectrometry (UV-3600, Shimadzu) or microplate reader (SpectraMax iD3). ${ }^{1} \mathrm{H}$ and ${ }^{13} \mathrm{C}$ NMR were performed on a Bruker DRX-400 spectrometer (Bruker) system. A matrix-assisted laser desorption/ionization time-of-flight mass spectrometer (ultrafleXtreme) was used for mass spectrometry. Fluorescence measurement was measured on a HITACHI F4600 fluorescence spectrophotometer at room temperature.

For cell and animal fluorescence images imaging, IVIS spectral imaging system was used:

Imaging parameters: Fluorescence;

Filter: Cy5.5 channel (690-770 nm);

Field of view: B;

Exposure time: 2s in Figure 3e and S13, 15s in Figure 5c;

Software: Living Image 4.0 software.

For photoacoustic imaging, a commercial small animal photoacoustic imaging system was used:

Model: MSOT inVision 256-TF (iThera Medical GmbH, Munich, Germany);

Optical parametric oscillator (OPO): Nd:YAG laser;

Excitation pulses: $9 \mathrm{~ns}$;

Wavelengths range: $680 \mathrm{~nm}$ to $980 \mathrm{~nm}$;

Repetition rate: $10 \mathrm{~Hz}$;

Wavelength tuning speed:10 ms;

Peak pulse energy: $100 \mathrm{~mJ}$;

Center frequency of ultrasound transducers: $5 \mathrm{MHz}$ (60\% bandwidth). 
Synthesis of ORM: ${ }^{1}$ Compound CS was prepared by reported method. ${ }^{2}$ In a threenecked flask, CS (10 mg) was added to $2 \mathrm{ml}$ anhydrous dichloromethane and $0.2 \mathrm{ml}$ ethanol in an ice bath under $\mathrm{N}_{2}$ atmosphere. Triethylamine $(100 \mu \mathrm{L})$ and trifluoromethanesulfonic anhydride $(100 \mu \mathrm{L})$ were slowly added to this system in sequence. The solution was stirred for $0.5 \mathrm{~h}$ at room temperature, and then was concentrated and extracted three times with saturated brine and dichloromethane. Finally, the residue was purified by silica gel chromatography with $\mathrm{CH}_{2} \mathrm{Cl}_{2} / \mathrm{CH}_{3} \mathrm{OH}$ $(\mathrm{v} / \mathrm{v}, 50: 1)$ as eluent to give a purple solid. ${ }^{1} \mathrm{H}$ NMR $\left(400 \mathrm{MHz}, \mathrm{CDCl}_{3}\right) \delta 8.67(\mathrm{~d}, \mathrm{~J}=$ $15.2 \mathrm{~Hz}, 1 \mathrm{H}), 8.26(\mathrm{~d}, \mathrm{~J}=7.8 \mathrm{~Hz}, 1 \mathrm{H}), 7.77$ (t, J = 7.3 Hz, 1H), 7.67 (t, J = $7.5 \mathrm{~Hz}$, 1H), 7.58 - $7.48(\mathrm{~m}, 4 \mathrm{H}), 7.27$ - $7.20(\mathrm{~m}, 2 \mathrm{H}), 6.87$ - $6.76(\mathrm{~m}, 2 \mathrm{H}), 4.24$ (dd, J = 14.0, $7.0 \mathrm{~Hz}, 2 \mathrm{H}), 4.09$ (s, 3H), 2.27 (d, J = 25.8 Hz, 4H), 2.03 (s, 2H), 1.86 (d, J = 4.0 Hz, $6 \mathrm{H}), 1.65(\mathrm{~s}, 3 \mathrm{H}) .{ }^{13} \mathrm{C} \mathrm{NMR}\left(100 \mathrm{MHz}, \mathrm{CDCl}_{3}\right) \delta 179.64,165.32,157.62,150.50$, $146.42,145.41,142.19,141.97,140.00,134.66,133.57,129.72,129.02,127.35$, $124.25,122.73,122.28,117.14,113.63,110.79,108.46,61.56,51.27,35.91,31.90$, $29.69,27.58,25.52,22.67,19.81,14.10,14.02$.

Synthesis of OIM: ${ }^{3}$ In a three-necked flask, 3,6-bis(5-trimethylstannylthien-2thienyl) -2,5-bis(2-decyltetradecyl)-2,5-dihydropyrrolo[3,4-c]pyrrole-1,4-dione (32.5 $\mathrm{mg}$ ), 4,8-dibromo-6-(2-ethylhexyl)-[1,2,5]thiadiazolo[3,4-f]benzotriazole (11.2 mg), and $\mathrm{Pd}\left(\mathrm{PPh}_{3}\right)_{4}(2 \mathrm{mg})$ were added into toluene $(5 \mathrm{ml})$ under an inert $\mathrm{N}_{2}$ atmosphere. The solution was stirred for 24 hours at $100{ }^{\circ} \mathrm{C}$, then bromobenzene and $(4,4,5,5-$ tetramethyl-1,3,2-dioxabo-rolan-2-yl)benzene were added dropwise. Next, the reaction system was concentrated and extracted three times with saturated brine and toluene. Finally, the reaction mixture was concentrated in vacuum to give a black solid OIM. ${ }^{1} \mathrm{H}$ NMR (400 MHz, $\mathrm{CDCl}_{3}$ ) $\delta 9.75$ - 8.68 (br, 4H), 5.42 - 4.77 (br, 2H), 4.61-3.66 (br, 4H), $2.73-0.62(\mathrm{br}, 109 \mathrm{H})$.

Preparation of RSPN. A tetrahydrofuran (THF) solution $(1 \mathrm{~mL})$ containing ORM $(70 \mu \mathrm{g})$, OIM $(35 \mu \mathrm{g})$ and DSPE-PEG $2000(350 \mu \mathrm{g})$ was quickly injected into deionized water $(9 \mathrm{~mL})$, under sonication. After sonication for 10 minutes, the solution was evaporated by rotary evaporator at $40^{\circ} \mathrm{C}$ to remove excess 
THF. Finally, the RSPN solution was purified three times by ultrafiltration (100 K MWCO, 5000 rpm).

Measurement of RSPN Responsive toward $\mathrm{O}_{2}{ }^{--} \mathrm{O}_{2}{ }^{*-}$ solutions with different concentrations was added into $200 \mu \mathrm{L}$ of PBS (pH 7.4) containing various concentrations of RSPN. The absorbance spectra of those solutions were recorded by UV-Vis absorption spectrometry. The PA images of those solutions were recorded at two excitation wavelengths of 690 and $800 \mathrm{~nm}$, respectively. For selective assay, various species were incubated with RSPN for 30 minutes, as following: 1. PBS, 2. $\mathrm{H}_{2} \mathrm{O}_{2}(200 \mu \mathrm{M}), 3$. $\bullet \mathrm{OH}(200 \mu \mathrm{M}), 4 . \mathrm{NaNO}_{2}(200 \mu \mathrm{M}), 5$. Cys $(200 \mu \mathrm{M}), 6$. Hcy $(200$ $\mu \mathrm{M})$, 7. $\mathrm{Na}_{2} \mathrm{~S}(200 \mu \mathrm{M}), 8$. NO $(200 \mu \mathrm{M}), 9$. ONOO- $(100 \mu \mathrm{M}), 10$. HClO $(100 \mu \mathrm{M})$, 11. $\mathrm{O}_{2}{ }^{\bullet-}(60 \mu \mathrm{M})$.

\section{Cellular experiments}

RAW 264.7 macrophages were cultured in DMEM medium supplemented with $10 \%$ fetal bovine serum (FBS) and 1\% antibiotics (penicillin-streptomycin).

For cytotoxicity assay, the macrophages were seeded in a 96 -well plate at a density of $1 \times 10^{4}$ cells per well, and cultured at $37^{\circ} \mathrm{C}$ in a $5 \% \mathrm{CO}_{2} / 95 \%$ air humidified incubator for 12 hours. Then, the DMEM medium was replaced by different concentrations of RSPN (0-40 $\mu \mathrm{g} / \mathrm{mL}$ of ORM) for further incubation with cells for 24 hours. Finally, the cell viability was assessed by standard MTT assay.

For imaging of $\mathrm{O}_{2}{ }^{-*}$ in macrophages, RAW 264.7 macrophages cells were treated as following: (1) No treatment; (2) Only incubation with RSPN (3.5 $\mu \mathrm{g} / \mathrm{ml}$ of ORM, 30 minutes); (3) Incubation with lipopolysaccharide (LPS, $10 \mu \mathrm{g} / \mathrm{mL}$ ) + interferon- $\gamma$ (IFN- $\gamma, 200 \mathrm{ng} / \mathrm{mL}, 12 \mathrm{~h}$ ), and then RSPN (3.5 $\mu \mathrm{g} / \mathrm{ml}$ of ORM, 30 minutes); (4) Incubation with lipopolysaccharide (LPS, $10 \mu \mathrm{g} / \mathrm{mL})+$ interferon- $\gamma$ (IFN- $\gamma, 200$ $\mathrm{ng} / \mathrm{mL}, 12 \mathrm{~h}$ ), 2,2,6,6-tetramethylpiperidine-N-oxy (TEMPO, $300 \mu \mathrm{M}, 12 \mathrm{~h}$ ), and then RSPN ( $3.5 \mu \mathrm{g} / \mathrm{ml}$ of ORM, $30 \mathrm{~min}$ ). Next, those cells were subsequently washed three times with PBS before imaging. For fluorescent imaging, those cells were observed by confocal laser scanning microscope (Nikon, Japan). The excitation filter was 640 
$\mathrm{nm}$, and the collection wavelength range was $663-738 \mathrm{~nm}$. For photoacoustic imaging, the cell suspensions were collected and added into $1 \mathrm{ml}$ centrifuge tube for centrifugation at $800 \mathrm{rpm}$ for 3 minutes. The cell precipitate was obtained for photoacoustic imaging (InVision 256-TF imaging system, obtained at 690 and 800 $\mathrm{nm})$.

\section{Animal experiments}

All animal experiments were in compliance with relevant laws and approved by the Institutional Animal Care and Use Committee of Hunan University (protocol number: SYXK 2018-0006). ApoE E $^{-/}$mice (5-8 weeks, male) were purchased from Nanjing Qingzilan Technology Co., Ltd. (Nanjing, China).

For PA imaging of $\mathrm{O}_{2}^{--}$in the LPS-induced acute inflammation mice model, we injected saline subcutaneously into the left thigh of the mice and lipopolysaccharide (LPS, $2 \mathrm{mg} / \mathrm{kg}$ ) into the right thigh, respectively $(\mathrm{n}=3)$. At 18 hours post injection of LPS or saline, RSPN was subcutaneously injected in the left and right thigh, respectively. Then, we collected photoacoustic signal of 690 and $800 \mathrm{~nm}$ at different time points.

For PA imaging of plaque-bearing mice, $\mathrm{ApoE}^{-/-}$mice were fed with high-fat diet (HFD) for 16 weeks to induce atherosclerosis. Then, plaque-bearing mice were intranasally instilled with $50 \mu \mathrm{g}$ LPS to construct plaque-bearing mice complicated with acute pneumonia model. The mice were divided into three groups $(n=3)$ for photoacoustic imaging in vivo: (i) Healthy mice, (ii) Plaque-bearing mice (16 weeks HFD fed), (iii) Plaque-bearing mice (16 weeks HFD fed) complicated with acute pneumonia (LPS stimulation). Finally, mice in different groups were intravenously injected with PBS containing RSPN (100 $\mu \mathrm{L}, 140 \mu \mathrm{g} / \mathrm{mL}$ of ORM), and PA images were recorded at 690 and $800 \mathrm{~nm}$ at different time points.

For fluorescence and PA imaging of aortas, those aortas of each group were separated after i.v. injection of RSPN for $1 \mathrm{~h}$. Ex vivo fluorescence imaging of the aortas were recorded using an IVIS spectral imaging system (Lumina XR), excitation wavelength at $640 \mathrm{~nm}$; PA images were obtained at 690 and $800 \mathrm{~nm}$. 
For white blood cell count in blood, tail blood was collected from healthy mice healthy mice, plaque-bearing mice and plaque-bearing mice complicated with pneumonia. The cell smears were observed and analyzed under a microscope. The number of white blood cells was counted in each field of view.

For measuring wet/dry weight ratio (W/D) of lungs, the fresh lung lobe tissues were separated and weighted to obtain the wet weight firstly. Then, the dry weight of lung lobe tissues was weighted after incubation at $80^{\circ} \mathrm{C}$ for $48 \mathrm{~h}$.

For hematoxylin-eosin (H\&E) staining, aortas were separated from mice of each group after i.v. injection of RSPN for $1 \mathrm{~h}$. Next, those aortas were fixed with paraformaldehyde for 30 minutes, embedded in OCT, frozen at $-20^{\circ} \mathrm{C}$ for 2 hours, sliced at a thickness of $5 \mu \mathrm{m}$, and finally, stained with H\&E, using the standard protocol. The fiber cap thicknesses and necrotic areas were measured by CaseViewer.

To evaluate systematic toxicity, $\mathrm{C} 57 \mathrm{bl} / 6$ mice $(\mathrm{n}=5)$ were i.v. injected with RSPN. At 1st or 7th day post injection, those mice were sacrificed and the blood samples $(\sim 1 \mathrm{~mL})$ were collected for blood biochemistry assay and complete blood panel analysis (Wuhan Service bio Technology Co., Ltd.). Untreated C57bl/6 mice were used as the control. Major organs (e.g., heart, liver, kidneys, lung and spleen) were collected from mice for H\&E staining at 1 st or 7 th day post i.v. injection of RSPN. 


\section{Supplementary Figure}

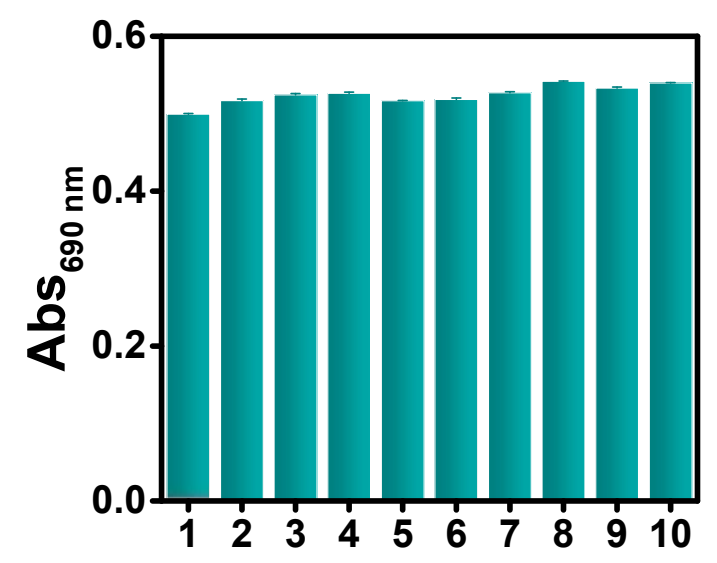

Figure S1 Stability response: absorbance at $690 \mathrm{~nm}$ of CS towards: various species were incubated with $\mathrm{CS}(5 \mu \mathrm{M})$ for 10 minutes in $\mathrm{MeOH}: \mathrm{PBS}=3: 7(\mathrm{v} / \mathrm{v})$, as following: 1. PBS, 2. $\mathrm{Cu}^{2+}(100 \mu \mathrm{M}), 3$. $\cdot \mathrm{OH}(100 \mu \mathrm{M}), 4 . \mathrm{NaNO}_{2}(100 \mu \mathrm{M}), 5$. Cys (100 $\mu \mathrm{M})$, 6. GSH $(100 \mu \mathrm{M})$, 7. $\mathrm{H}_{2} \mathrm{O}_{2}(100 \mu \mathrm{M}), 8 . \mathrm{O}_{2}{ }^{--}(100 \mu \mathrm{M})$, 9. tBuOOH $(100$ $\mu \mathrm{M}), 10$ ONOO- $^{-}(100 \mu \mathrm{M})$. 
(a)

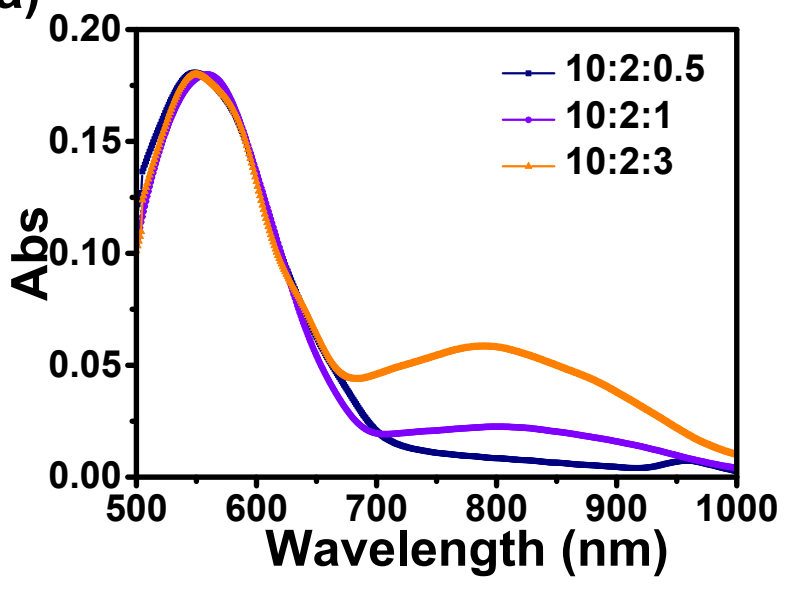

(b)

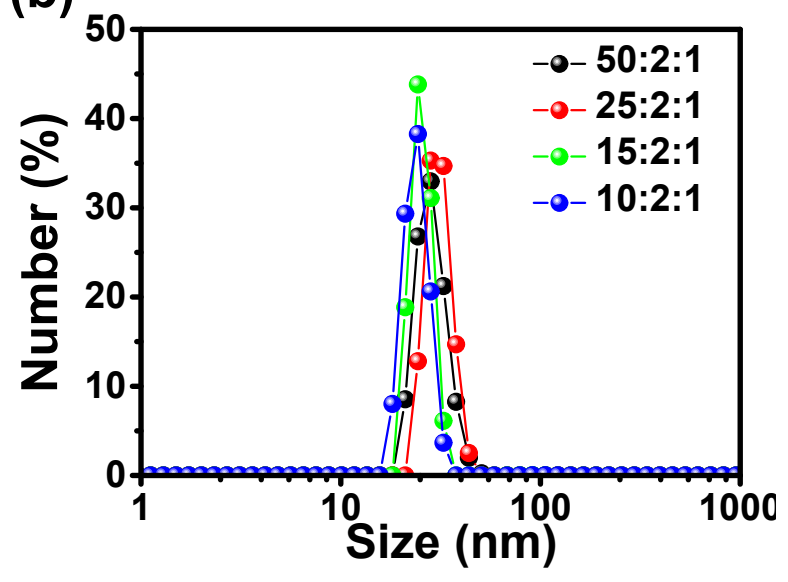

Figure S2 Absorption spectrum(a) and hydrodynamic size(b) of RSPN at different DSPE-PEG $_{2000}$ : ORM: OIM mass ratios. 


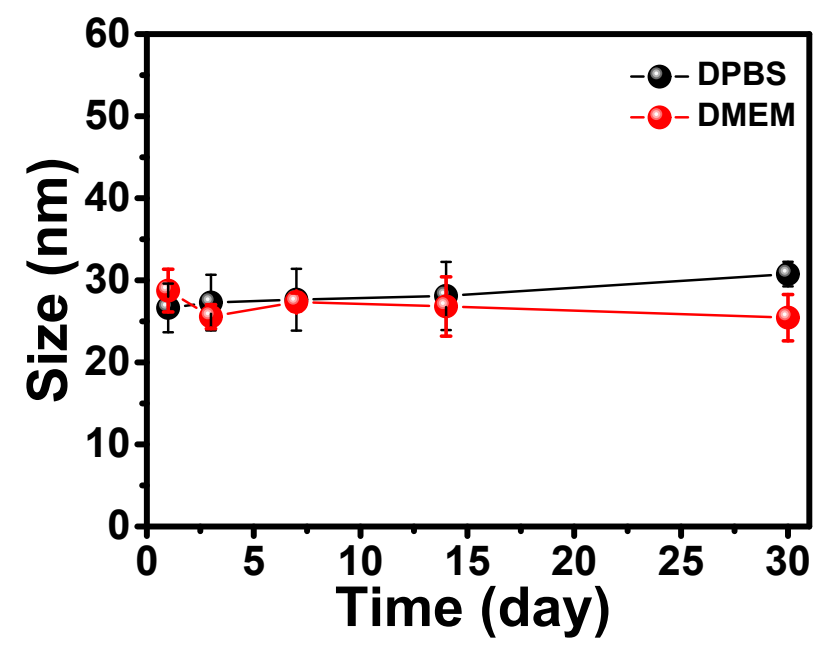

Figure S3 Hydrodynamic size of RSPN in DPBS and DMEM cell culture medium. 


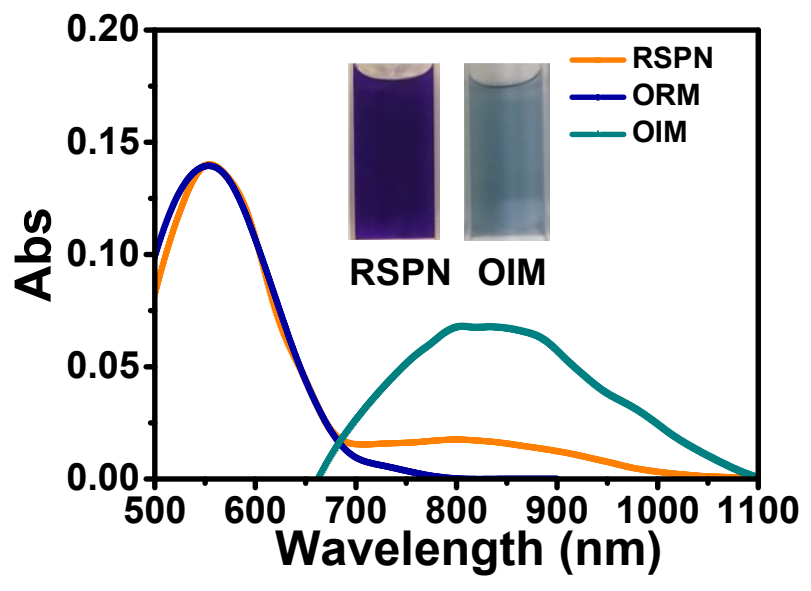

Figure S4 Absorption spectra of RSPN, ORM and OIM. Inset are photos of RSPN (left) and OIM (right). 


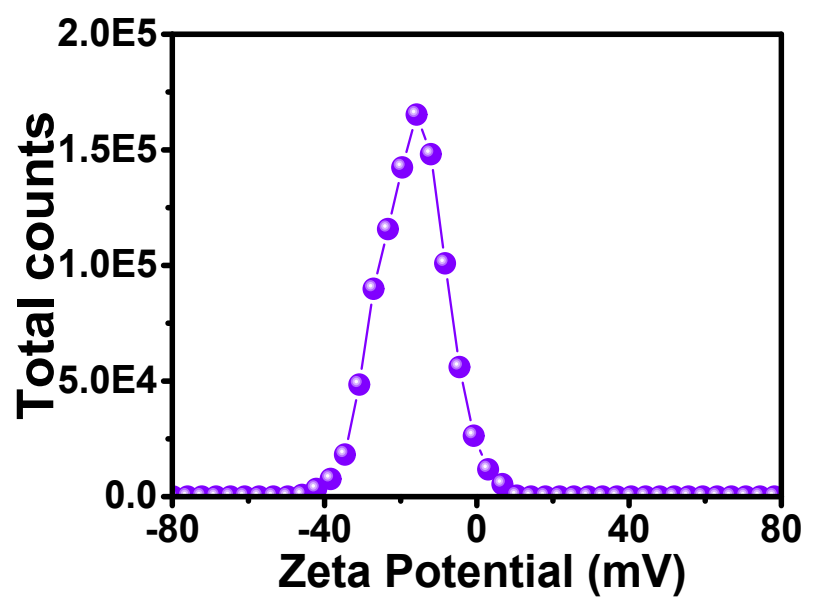

Figure S5 Zeta potential of RSPN in water. 


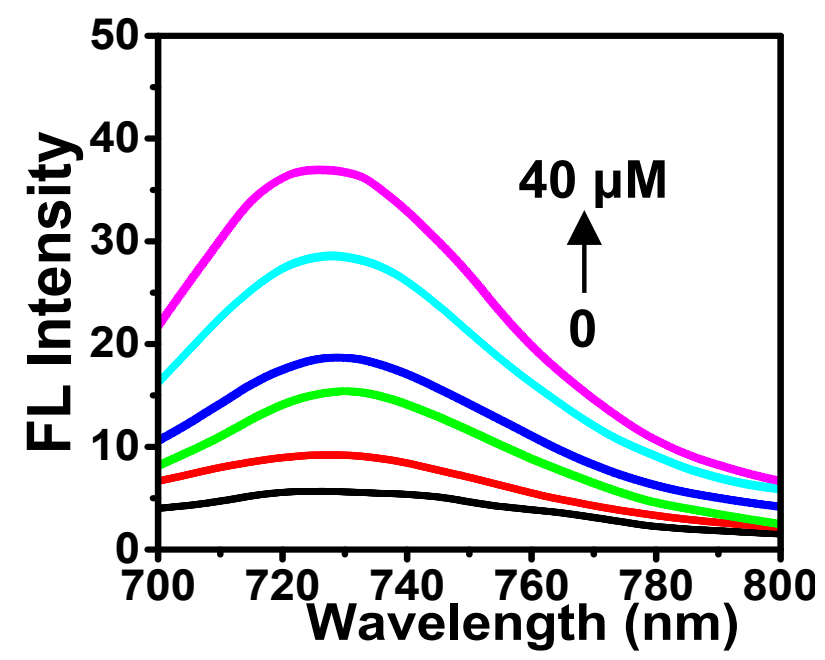

Figure S6 Fluorescence emission spectra of RSPN ( $7 \mu \mathrm{g} / \mathrm{ml}$ of ORM) with different concentrations of $\mathrm{O}_{2}{ }^{\circ-}$. (Excitation wavelength $\left.=680 \mathrm{~nm}\right)$ 

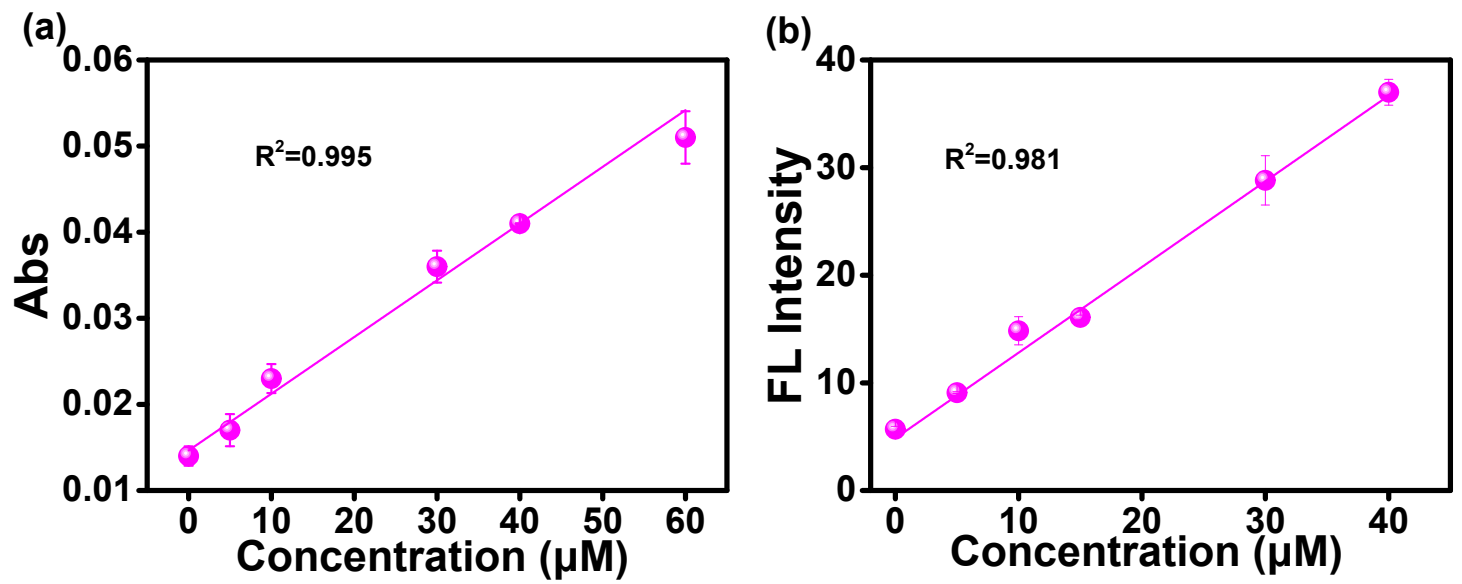

Figure S7 Linear relationship for the absorbance at $690 \mathrm{~nm}$ (a) or fluorescence emission intensity at $725 \mathrm{~nm}$ (b) of RSPN with $\mathrm{O}_{2}{ }^{--}$concentration. 

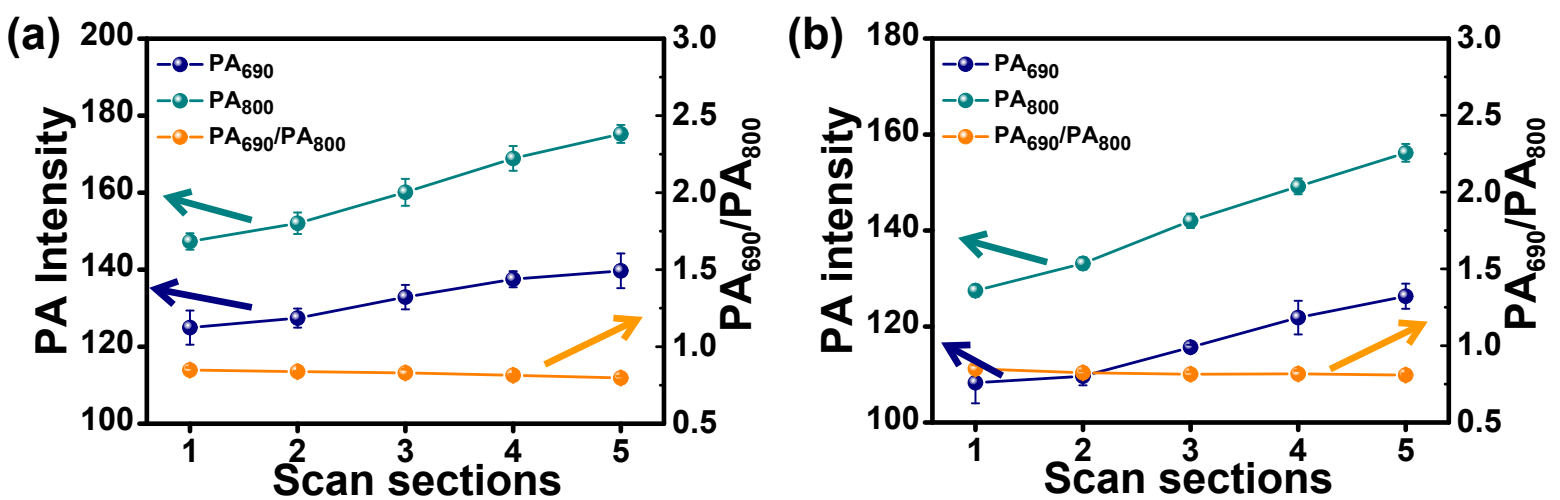

Figure S8 Quantification of $\mathrm{PA}_{690}, \mathrm{PA}_{800}$ and $\mathrm{PA}_{690} / \mathrm{PA}_{800}$ ratios of $\mathrm{RSPN}$ in different scan sections and condition: (a) deionized water, (b) PBS. 


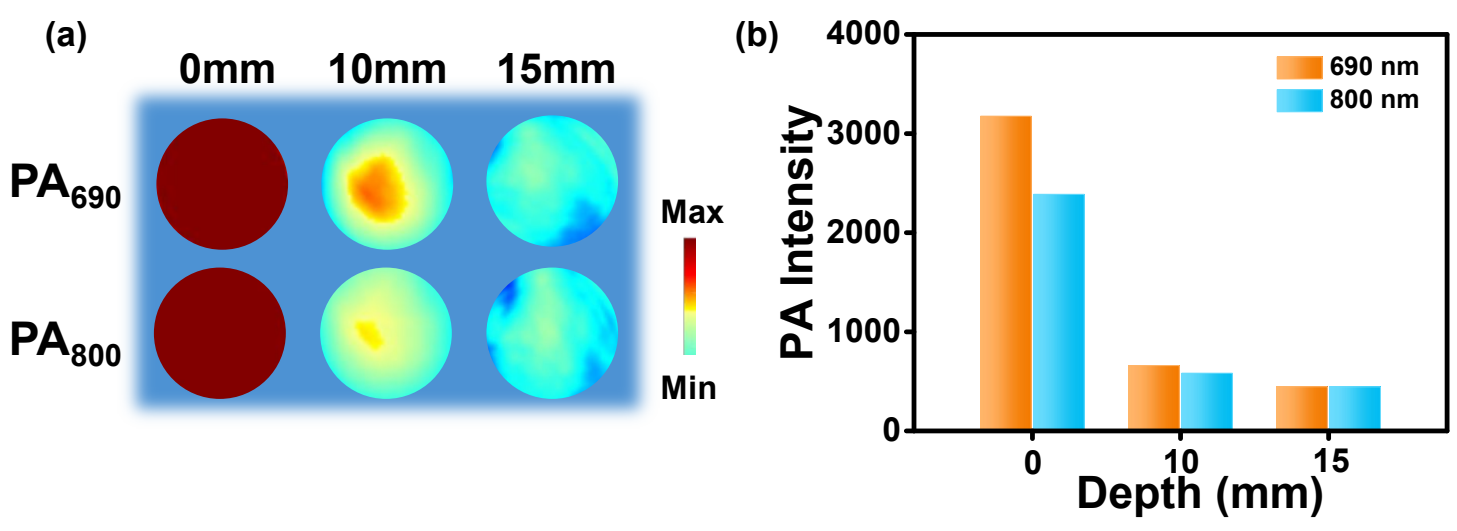

Figure S9 Tissue penetration of PA imaging. The PA images (a) and corresponding intensities (b) of tubes containing RSPN treat with $\mathrm{O}_{2}{ }^{\cdot-}$ covered with different thickness of chicken. 
Healthy mice

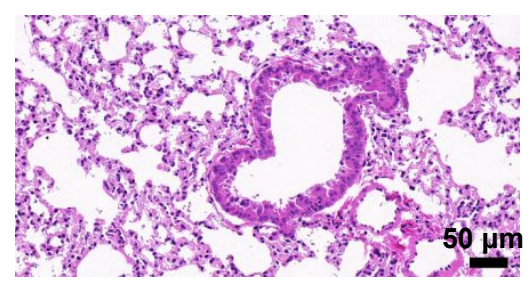

Plaque-bearing mice

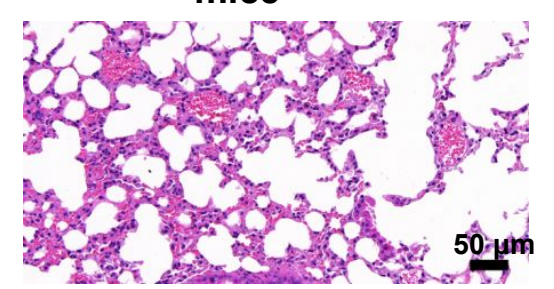

Plaque-bearing mice

+ pneumonia

Figure S10 H\&E staining images of lungs with different treatment. 

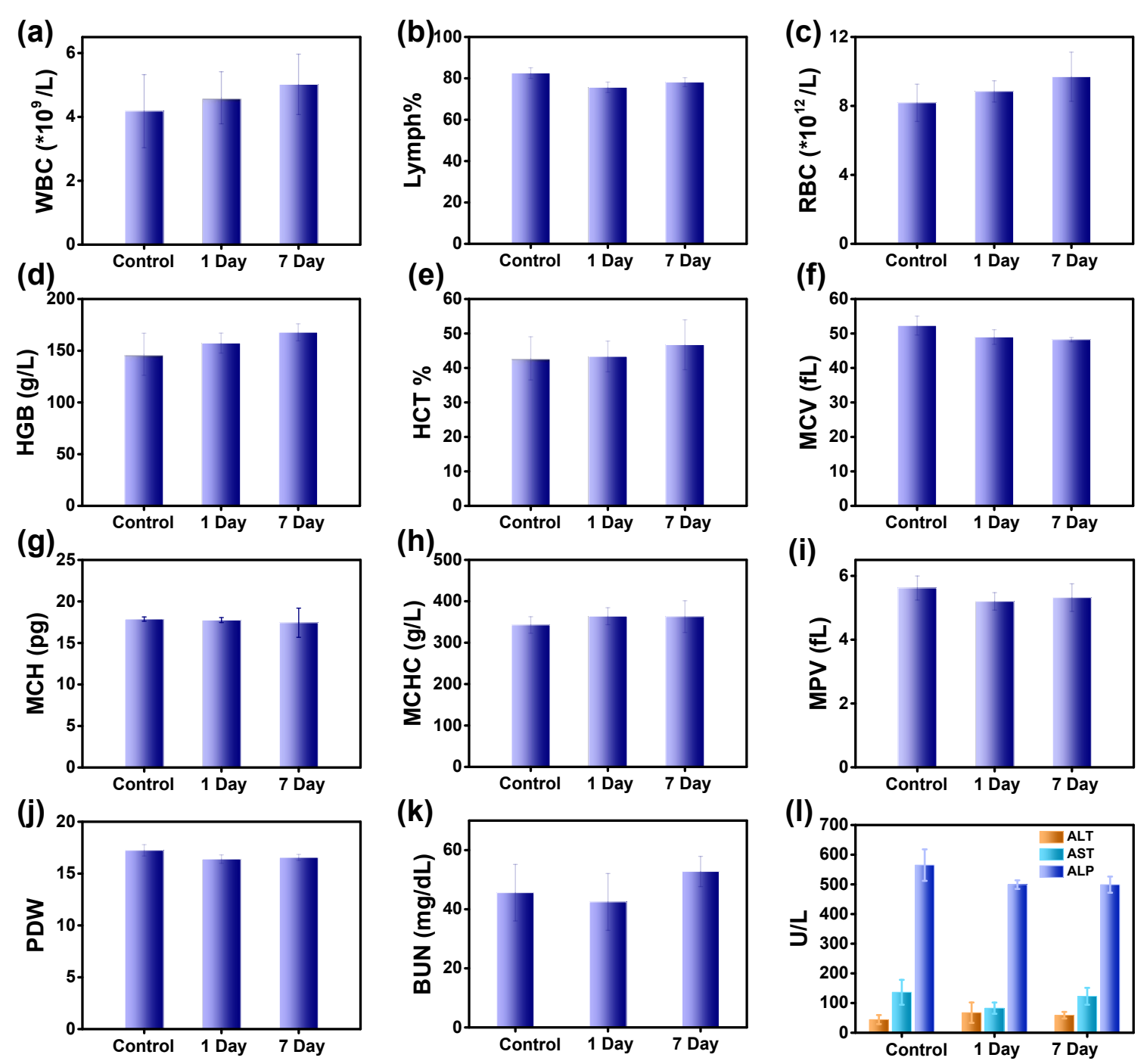

Figure S11 Complete blood panel analysis and blood biochemistry of control mice, and mice i. v. injected with RSPN at 1st or 7th day. (a) white blood cells (WBC); (b) percentage of lymphocytes (Lymph \%); (c) red blood cells (RBC); (d) hemoglobin (HGB); (e) hematocrit (HCT); (f) mean corpuscular volume (MCV); (g) mean corpuscular hemoglobin $(\mathrm{MCH})$; (h) mean corpuscular hemoglobin concentration (MCHC); (i) mean platelet volume (MPV); (j) platelet distribution width (PDW); (k) blood urea nitrogen (BUN); (l) alkaline phosphatase (ALP), alanine aminotransferase (ALT), and aspartate aminotransferase (AST). 


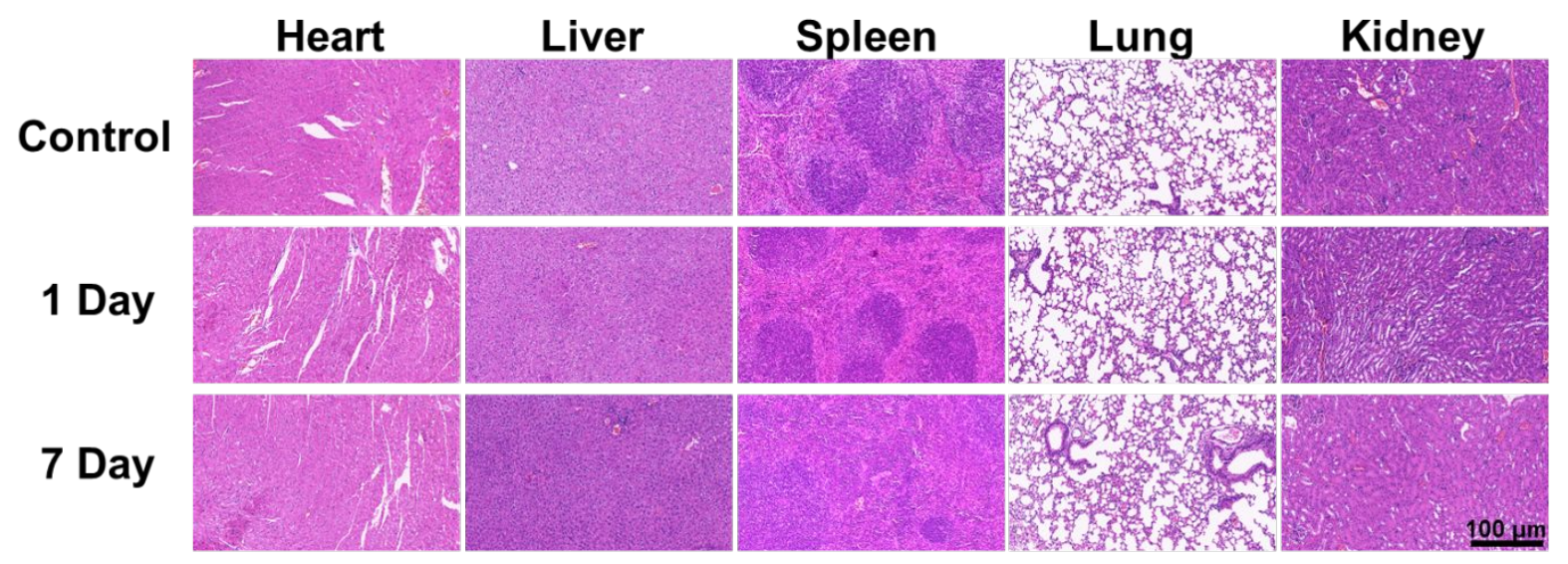

Figure S12 H\&E-staining images of major organs from control mice, and mice i. v. injected with RSPN at 1st or 7th day. 


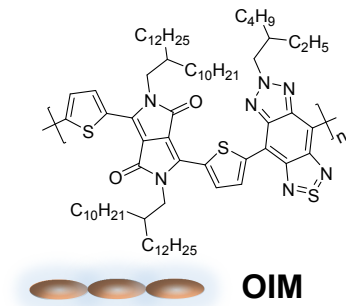

DSPE-PEG 2000
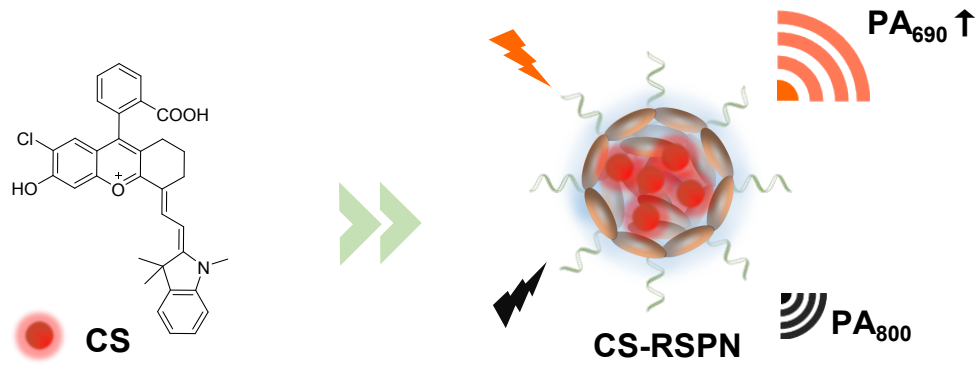

Figure S13 The chemical structure of CS, OIM and the synthetic route for CS-RSPN. 
(a)

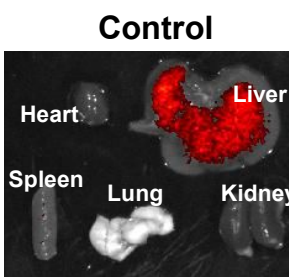

$1 \mathrm{~d}$

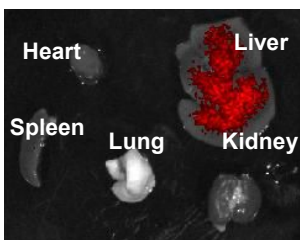

$1 \mathrm{~h}$

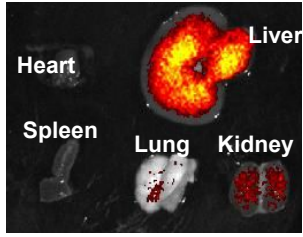

$7 \mathrm{~d}$

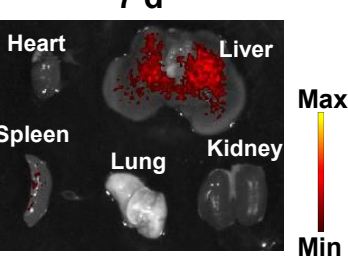

(b)

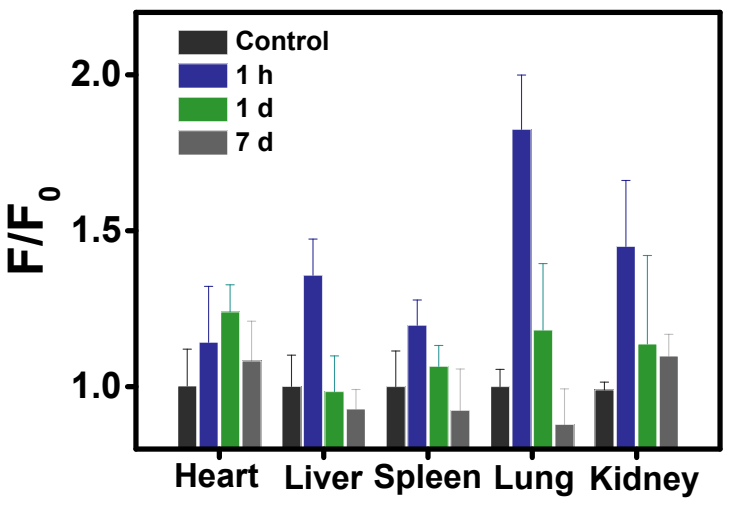

Figure S14 C57bl/6 mice ( $=3)$ were i.v. injected with CS-RSPN. At 1 h, 1 day or 7 days post injection, those mice were sacrificed and main organs were collected for imaging. Untreated C57b1/6 mice were used as the control. (a) Fluorescent images of major organs from control mice, and mice i. v. injected with CS-RSPN at $1 \mathrm{~h}, 1$ st or 7th day $(E x=640 \mathrm{~nm}, E m=690-770 \mathrm{~nm})$. (b) Quantification of mean F/F0 in (a). (F/F0 was calculated by dividing the fluorescence intensity of the experimental group by that of control organs). 


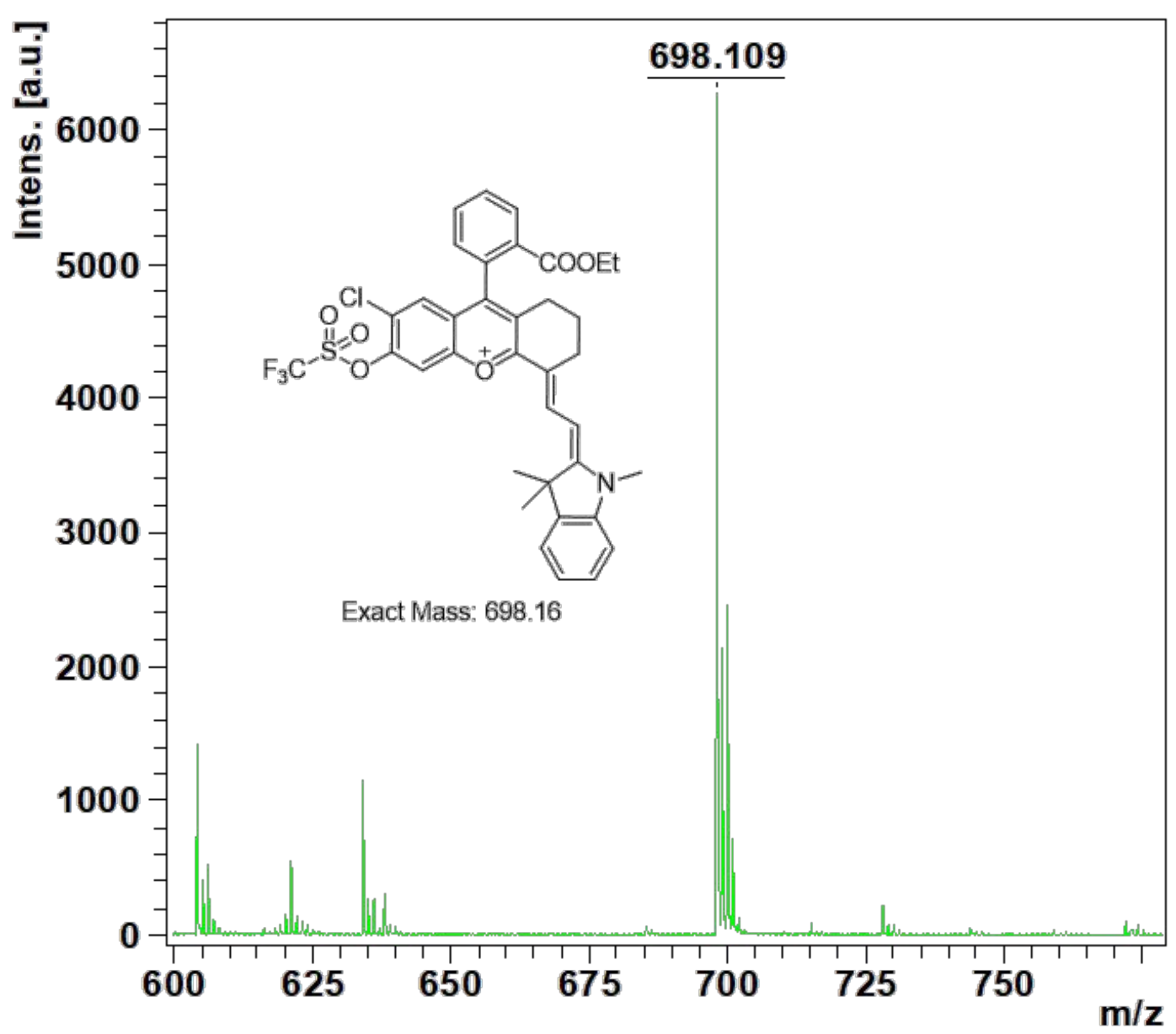

Figure S15 MALDI-TOF mass spectrum of ORM 


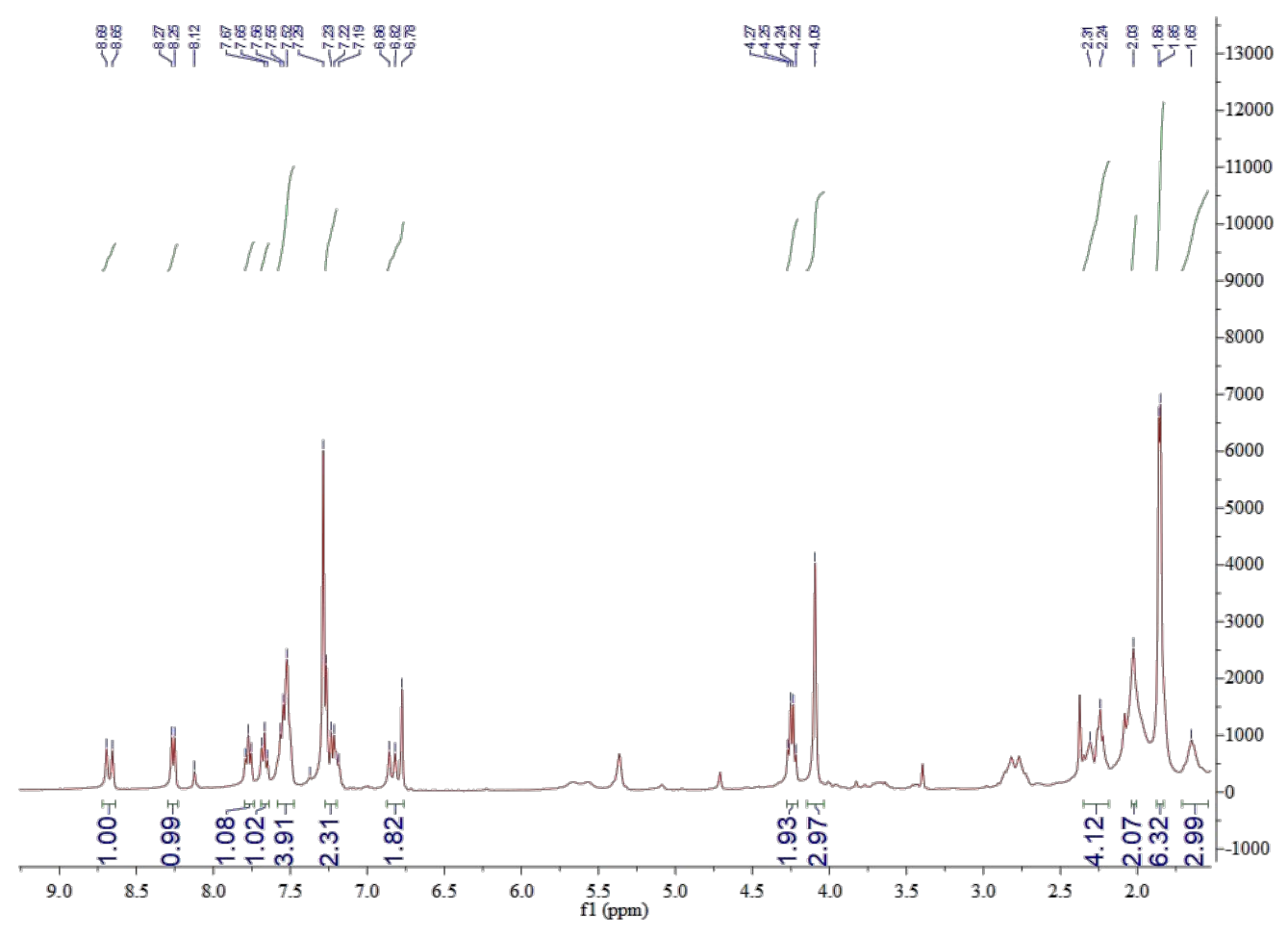

Figure S16 ${ }^{1} \mathrm{HNMR}$ spectrum of ORM. 


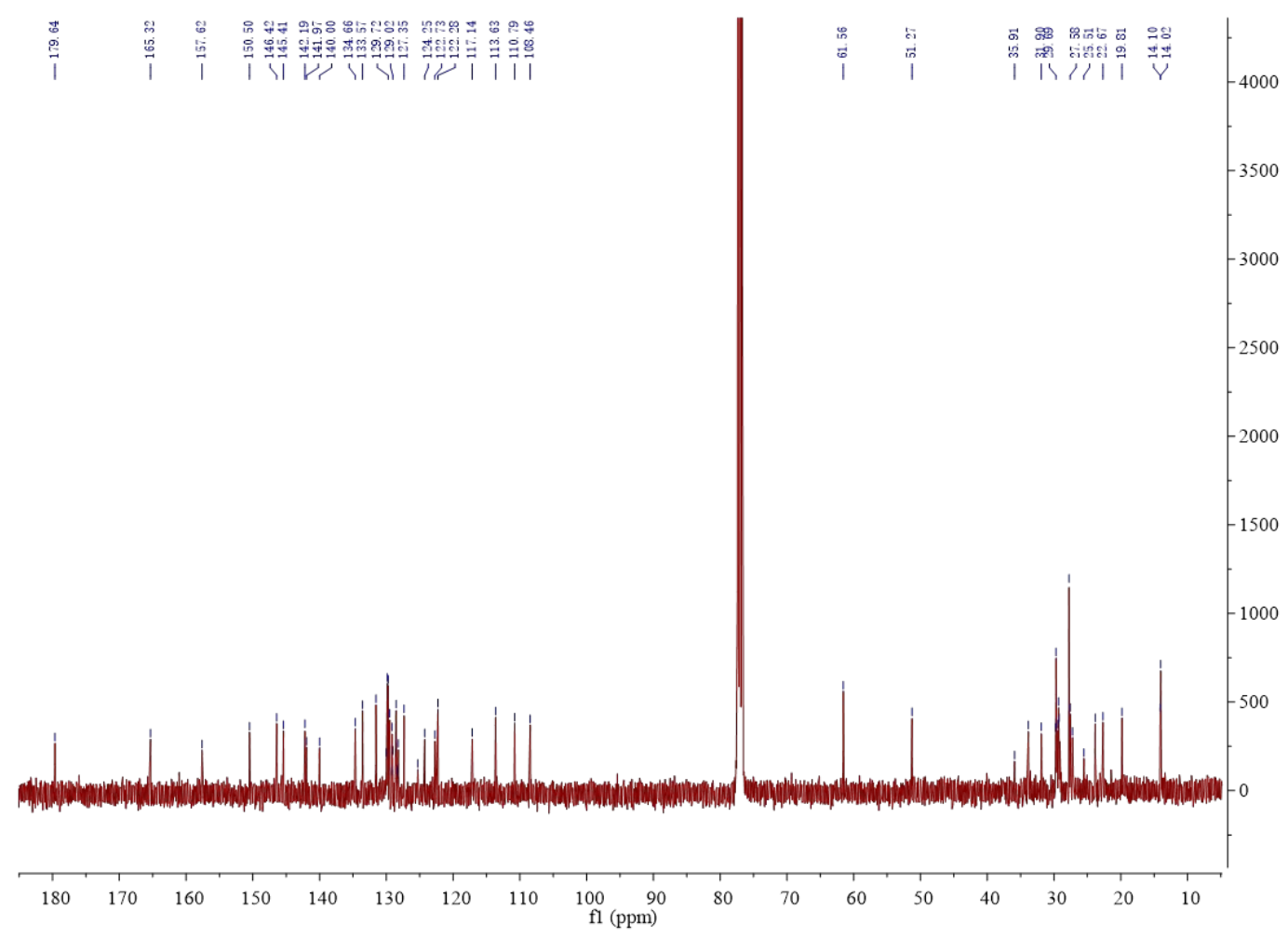

Figure S17 ${ }^{13} \mathrm{CNMR}$ spectrum of ORM. 


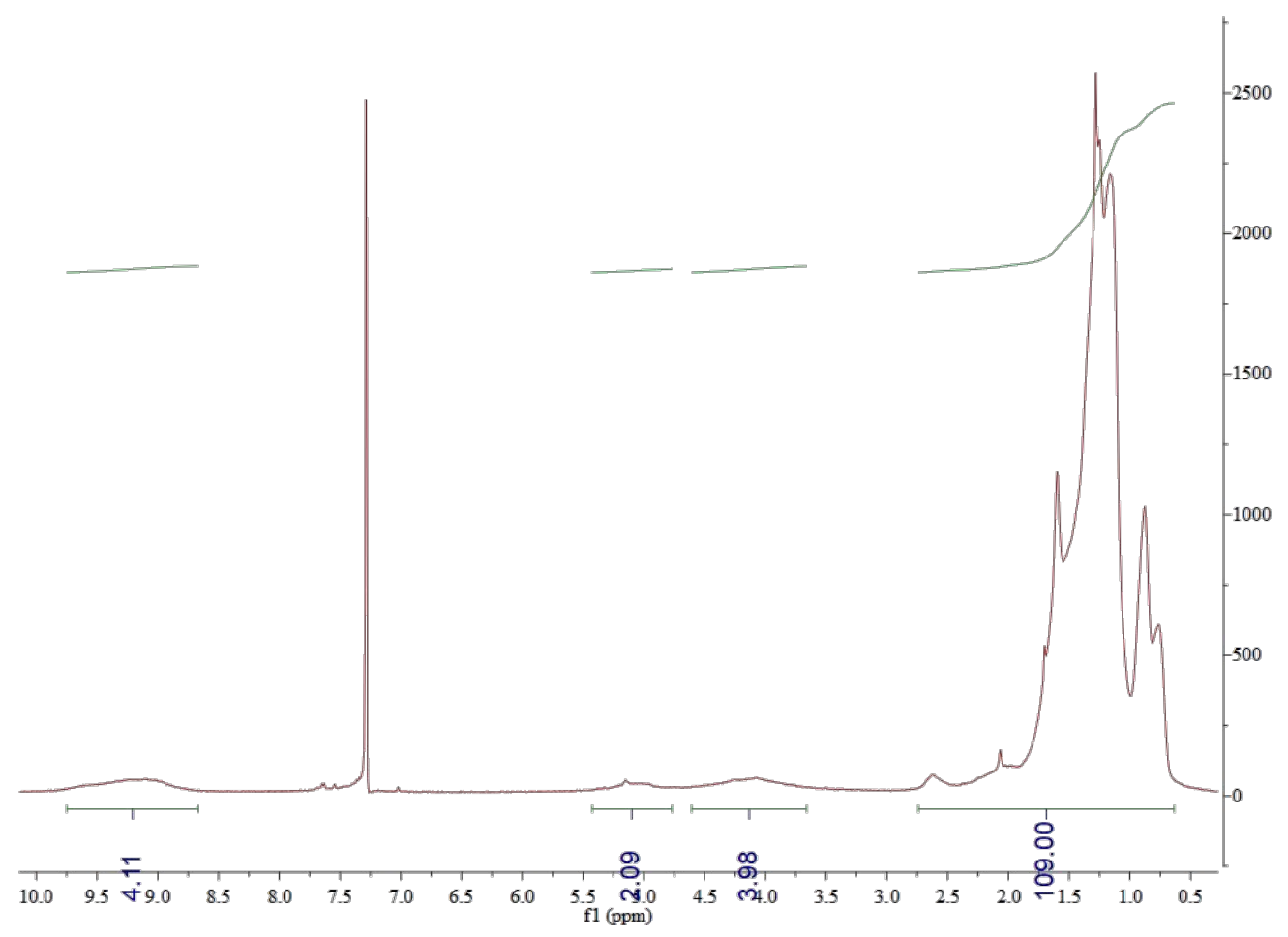

Figure S18 ${ }^{1} \mathrm{HNMR}$ spectrum of OIM. 


\section{REFERENCES}

(1) Lv, Y.; Dan, C.; Dongdong, S.; Chen, M.; Yin, B. C.; Yuan, L.; Zhang, X. B. Visualization of oxidative injury in the mouse kidney using selective superoxide anion fluorescent probes. Chem. Sci. 2018, 9, (39), 7606-7613.

(2) Xiong, X.; Song, F.; Chen, G.; Sun, W.; Wang, J.; Gao, P.; Zhang, Y.; Qiao, B.; Li, W.; Sun, S.; Fan, J.; Peng, X. Construction of Long-Wavelength Fluorescein Analogues and Their Application as Fluorescent Probes. Chem. Eur. J. 2013, 19, (21), 6538-6545.

(3) Men, X.; Wang, F.; Chen, H.; Liu, Y.; Men, X.; Yuan, Y.; Zhang, Z.; Gao, D.; Wu, C.; Yuan, Z. Ultrasmall Semiconducting Polymer Dots with Rapid Clearance for Second Near-Infrared Photoacoustic Imaging and Photothermal Cancer Therapy. $A d v$. Funct. Mater. 2020, 30, (24), 1909673. 